\title{
Editorial
}

\section{Desafios para a gestão de periódicos científicos no Brasil e a importância de seu financiamento}

\author{
Mário César Rezende Andrade
}

Editor executivo

A produção científica brasileira tem experimentado ganhos e perdas nas últimas décadas. Após um período de notável crescimento da produção de artigos e do número de periódicos científicos no país, que chegou a ocupar a $13^{\mathrm{a}}$ posição no ranking mundial de produção científica (Packer, 2011), em anos bem recentes, os periódicos nacionais têm enfrentado várias dificuldades para sua manutenção. Tais dificuldades acompanham os cortes dos investimentos na área científica e tecnológica. Entre os principais desafios enfrentados pelos editores dos periódicos nacionais, especialmente aqueles com acesso livre, destaca-se a escassez, cada vez maior, de suporte financeiro (Kellner, 2017).

Nos últimos anos, o crescimento da produção científica nacional, que se fez presente também na Psicologia, teve como reflexo o aumento significativo de submissões e de filas para publicação dos artigos, o que, junto à necessidade de qualificação das publicações, consiste em um desafio adicional para o fluxo editorial dos periódicos. Apesar da crescente e contínua informatização dos processos editoriais, a oferta de financiamento e o fomento dos periódicos nunca foram tão essenciais para sua sobrevivência no contexto atual (Packer, 2014).

Nesse cenário, a Gerais: Revista Interinstitucional de Psicologia, como periódico científico de livre acesso da área de Psicologia, conta com a colaboração regular e essencial do Setor de Editoração Eletrônica (SEDIT) da Universidade Federal de São João del-Rei (UFSJ), além de recorrer a editais de fomento, indispensáveis para garantir a integridade do processo editorial. Entre esses editais, obtivemos recentemente o suporte financeiro do edital 01/2019 da Associação Nacional de Pesquisa e PósGraduação em Psicologia (ANPEPP), esteio que viabilizou o processo editorial dos números 13(2), 13(3), 14(1) e 14(2). À propósito, com esse suporte, será possível a publicação de 16 artigos, ao invés de 12, no presente número, 13(3), referente ao último quadrimestre de 2020, assim como nos números referentes aos dois primeiros quadrimestres de 2021, especificamente, 14(1) e 14(2). A publicação de quatro artigos adicionais em cada um dos números citados possibilitará um adiantamento na fila de publicação da revista.

Além disso, recebemos o apoio do Departamento de Psicologia da UFSJ, por meio do suporte financeiro para "Contratação de prestação de serviços não contínuos" (processo número 23122.019742/2020-80), que assegurará parte do processamento do número $14(2)$ e de um número especial, 14(S), a ser publicado no ano de 2021, incluindo apenas artigos de revisão da literatura. Por fim, obtivemos a liberação dos recursos do Edital 
05/2017, da Fundação de Amparo à Pesquisa do Estado de Minas Gerais (FAPEMIG), pelo "Programa de apoio a publicações científicas e tecnológicas, publicação de periódicos institucionais". O apoio desse órgão contribuirá para o processamento editorial de alguns dos números seguintes da revista. Portanto, o apoio financeiro é uma pedra fundamental para a viabilização dos fluxos editoriais, após a aprovação dos artigos, e para a existência dos periódicos científicos no contexto atual.

\section{Referências}

Kellner, A. W. A. (2017). Editors of Brazilian journals - a hard life that is getting harder! Anais da Academia Brasileira de Ciências, 89(1), 1 2. https://doi.org/10.1590/0001$\underline{37652017891}$

Packer, A. L. (2011). Os periódicos brasileiros e a comunicação da pesquisa nacional. Revista USP, (89), 26-61. Recuperado em 29 janeiro, 2021, de http://rusp.scielo.br/scielo.php?script=sci a rttext\&pid $=\mathrm{S} 0103-$ 99892011000200004\&lng $=$ en\&tlng $=$ pt

Packer, A. L. (2014). A eclosão dos periódicos do Brasil e cenários para o seu porvir. Educaşão e Pesquisa, 40(2), 301-323. https://doi.org/10.1590/S1517$\underline{97022014061860}$ 